\title{
The Calibration Process of OSL Detectors used for Staff and Patient Dosimetry in Hospital Environment
}

\author{
Nina Tuncel ${ }^{1 *}$, Binnur Karayalcin ${ }^{2}$ and Gulsah koca ${ }^{1}$ \\ ${ }^{1}$ Department of Physics, Faculty of Science, Akdeniz University, Antalya, Turkey \\ ${ }^{2}$ Department of Nuclear Medicine, Akdeniz University Medical School, Antalya, Turkey
}

*Corresponding author: Nina Tuncel, Assistance Professor, Department of Physics, Faculty of Science, Akdeniz University, Antalya, Turkey, Tel: 00905325898466; Email: ninatuncel@akdeniz.edu.tr

Received date: Sep 16, 2015, Accepted date: Oct 29, 2015, Publication date: Nov 04, 2015

Copyright: (c) 2015 Tuncel N, et al. This is an open-access article distributed under the terms of the Creative Commons Attribution License; which permits unrestricted use; distribution; and reproduction in any medium; provided the original author and source are credited.

\begin{abstract}
The optically stimulated luminescence (OSL-BeO) dosemeter is increasingly being used as a dosimetric technique in various fields such as medical dosimetry. According to our fixed dose protocol, the activities of 3.7-7.4 GBq I-131 source is used for thyroid carcinoma therapy. The in house calibration process for usage of OSL's at hospital was arranged according to the encapsulated I-131. The measurement point was planned in three different radial distances from source free in air. The dose-rate measurement was done by Geiger-Muller (GM), and then three pieces of OSL was placed in the same positions for one hour. The inverse square law consistency was found $\left(R^{2}=0.99\right)$. The calibration coefficient was calculated. For determining the performance of OSL at different dose rates, it used for personnel and patient dosimetry. The average annual dose/2mon to the whole body for all staff by OSL were $0.80 \mathrm{mSv}$. After administration of $3.7 \mathrm{GBq}(100 \mathrm{mCi})$ therapeutic dose to selected patients, the average pectoral dose was $97.5+32.6 \mathrm{mSv}$. This calibration process is helpful for confidence of OSL detectors used for dosimetry of staff and patients treated with high activity I-131.
\end{abstract}

Keywords: Optically Stimulated Luminescence (OSL); OSL-BeO; Iodine-131; Calibration process of OSL detectors; Dosimetry of staff and patients

\section{Introduction}

In Nuclear medicine (NM) several unsealed radioactive sources for diagnosis or therapy purposes are used. In NM, radiation protection of workers is a main concern [1]. NM staff work daily with radioactive isotopes, and therefore receive a certain amount of radiation dose in line with carrying out a variety of tasks associated with each nuclear medicine procedure [2]. In this field, the associated radionuclide activities are ranged from few tens to several thousands of MBq.

The Iodine-131 is the most frequently used source for thyroid carcinoma therapy. In the fixed dose protocol an activity of 3.7-7.4 $\mathrm{GBq}(100-200 \mathrm{mCi}) \mathrm{I}-131$ is administered. Beta emission is often the dominant radiation for treatment, although the associated gamma emission gives rise to exposures to other tissues and even to other individuals.

Optically Stimulated Luminescence (OSL) is the transient luminescence observed during illumination of crystalline insulators or semiconductors that were previously excited; typically by exposure to ionizing radiation [3]. The optically stimulated luminescence (OSL$\mathrm{BeO}$ ) dosemeter is increasingly being used as a dosimetric technique in various fields such as medical and environmental dosemeter. Since 1990s OSL dosemeters are finding more and more applications in the field of personnel and environmental monitoring as well as in the field of medical physics [4]. In general, the key features of OSL that make it so attractive for personal dosimetry include the ability to tune the performance across a wide dynamic dose range by being able to vary the stimulation power. This allows optimum sensitivity at both the low- dose and the high- dose ends of the dose response. Furthermore, by adjusting the stimulation power appropriate to the dose range, one has the ability to re-read the OSL signal since the high sensitivity allows dose assessment even though only a fraction of the stored charge is depleted during the measurement. Thus, a complete re-analysis is achieved correctly and independent dose readings are possible [4]. For more than ten years a valuable dosimetric method employing optically stimulated luminescence (OSL) of the material beryllium oxide $(\mathrm{BeO})$ has been developed at Technical University Dresden (TU Dresden) [5-8]. Due to the near tissue equivalence of the material $\mathrm{BeO}$, the method promises to be useful for personnel dosimetry, too [8].

This study aimed to the in house calibration process for usage of OSL's at hospital according to the encapsulated Iodine-131 radioactive source which is used in nuclear medicine department. This process is helpful for confidence of OSLs used for dosimetry of staff and patients treated with diagnostic or therapeutic activity I-131.

\section{Material and Methods}

In this study the therapeutic activity, with initial activity around 3.7 $\mathrm{MBq}$, encapsulated I-131 was used as calibration source. All radioiodine sources are supplied by EZACIBASI/MONROL with trade name of MON.IYOT-131 Oral Capsule with an activity certification. This certificate determines the source initial activity at the date of product with $5 \%$ uncertainty. At the calibration operation the activity of source was calculated and it was $2.201 \mathrm{GBq}(59.54 \mathrm{mCi})$. This source was placed in Plexiglas tube. The measurement point was planned in different radial distances which are $30 \mathrm{~cm}, 50 \mathrm{~cm}$ and $100 \mathrm{~cm}$ from source free in air. These positions were used to measure dose rate by NEB.211 model Geiger-Muller (GM) detector that produced by Turkish Atomic Energy Authority (TAEA). This detector was calibrated at Secondary Standard Dosimetry Laboratory (SSDL) of 
TAEA with Cs-137 calibration source. The uncertainly along $0.5 \mathrm{mR} /$ $\mathrm{h}-1.5 \mathrm{R} / \mathrm{h}$ dose rate range was mentioned as $0-3.3 \%$ respectively in calibration certificate. On the other hand 3 pieces of OSL with cover carrier which are used in calibration process was placed in the same positions, Figure 1. The irradiation exposure time was one hour for all of OSLs. The OSLs were supplied by a private organization and the reading process was performed by them free of charge. The disk shape OSL samples have $0.5 \mathrm{~cm}$ diameter with $0.1 \mathrm{~cm}$ thickness. The dose values that reported were based on $\mathrm{Hp} 10$ and $\mathrm{Hp} 007$ as mSv. The standard calibration process of OSL system was carried on their manufacturer laboratory (http://www.radkor.com).

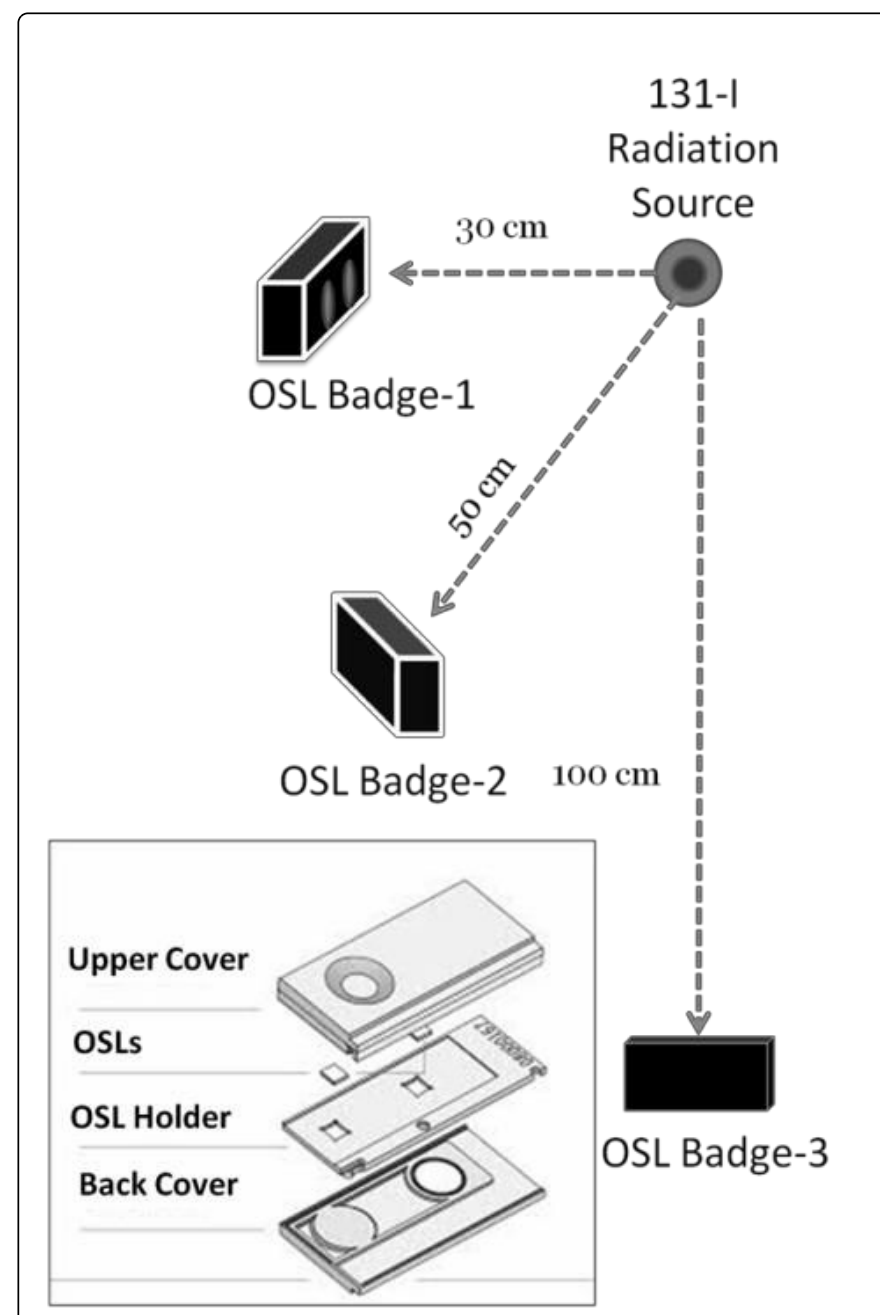

Figure 1: The calibration geometry for GM and OSL measurement was illustrated and the inserted picture shows the parts of an OSL badge.

Before calibration process, the background values were measured by two type detectors (GM and OSL) in the room which planned to perform this process.

For the first step at calibration process, the dose rate calculation of an isotropic point source was preferred for I-131 source with specified activity at three distances by using Equation (1). Hence, at the measurement practice the dose rate value was important not only by the distance but also by the direction. So the agreement between calculation and measurement were confirmed according to these parameters. At Eq1 the Epoint is dose rate from point source based on $\mathrm{R} / \mathrm{h}$ and it was calculated for $30 \mathrm{~cm}, 50 \mathrm{~cm}$ and $100 \mathrm{~cm}$ distances. And then, the dose rate $(\mathrm{R} / \mathrm{h})$ measurements at three different radial distances were done by GM at calibration distances. So the spatial distribution of dose (dose rate) at the calibration geometry that arranged for set-up of a selected source was considered.

Calculation of dose rate due to exposure to a point source at the distances that was mentioned for the calibration process was carried by following equation.

$$
\mathrm{E}_{\text {point }}=\mathrm{A} \times \hat{\Gamma} / \mathrm{d}^{2}(1) \text { Where }
$$

$\mathrm{E}_{\text {point }}=$ Dose rate from point source $[\mathrm{R} / \mathrm{h}]$

$\mathrm{A}=$ Source activity $[\mathrm{mCi}]$

$\hat{\Gamma}=2.27[(\mathrm{R}) /(\mathrm{mCi}) .(\mathrm{h})]$ Specific Gamma Constants at $1 \mathrm{~cm}$ for $131-\mathrm{I}$ [9]

\section{$\mathrm{d}=$ Distance from the point source $[\mathrm{cm}]$}

The converted GM reading and the calculated dose rate values according to $(\mathrm{cG} / \mathrm{h})$ at calibration points were done by using nuclidespecific $\mathrm{f}$-factor that is 0.963 (cGy/R) for I- 131 .

$\mathrm{f}=0.963[(\mathrm{cGy} / \mathrm{R})]$ Conversion factor [10].

And by considering conversion coefficient as one $(\mathrm{Gy}=\mathrm{Sv})$ the values were transferred to equivalent dose and then the comparisons with the equivalent dose value ( $\mathrm{mSv}$ ) of OSL along one hour at the same calibration positions was evaluated. The constancy of these values based on "Inverse Square Low" (ISL) principle was performed.

The calibration factor for OSL Hp10 values regarding calculation and GM values was obtained as 0.89 (uncertainty $3.7 \%$ ) and 0.92 (uncertainty $15.45 \%$ ) respectively.

This study also encompasses the dose results from OSL for one year to nuclear medicine department staff (9 persons), besides the thermoluminescence dosemeter

(TLD) badges that were supplied by Turkish Atomic Energy Authority (TAEA) for whole body personnel dose monitoring. In a typical yearly workload, the average annual dose $/ 2 \mathrm{mon}$ to the whole body for all staff by OSL was analyzed.

To recognize the high dose response of OSL's, this study includes the cumulative radiation dose received by treated patients with $3.7 \mathrm{GBq}$ ( $100 \mathrm{mCi}$ ) activity I-131 by using OSL for each day. The OSL badge dosemeter was placed on the left pectoral muscle. Depending on the treatment period, each patient used 2-3 OSL dosemeters. Totally, this dose analyzing method was performed on 5 patients by daily tracing. Generally The patient's dose measurements was done by using GM at 1 meter and /or other detectors, so did not need any ethical consensus.

\section{Results}

The mean and standard deviation (SD) of background value by GM that was measured before calibration process in measurement room was $0.11+0.022 \mathrm{mR} / \mathrm{h}$. The reading of GM at calibration situations was corrected by subtracting of this background value. The corrected reading from $2.201 \mathrm{GBq}$ I-131 source at different radial distances with $30 \mathrm{~cm}, 50 \mathrm{~cm}$ and $100 \mathrm{~cm}$ free in air was $136.9 \mathrm{mR} / \mathrm{h}, 54.9 \mathrm{mR} / \mathrm{h}$ and $15.5 \mathrm{mR} / \mathrm{h}$ respectively.

The mean dose value obtained from non-irradiated OSL readings based on Hp10 and Hp 007 was 0.12 and $0.11 \mathrm{mSv}$ respectively for two 
Page 3 of 3

months period. This value was considered as cumulative background value due to radiation background and systematic reading noise. Thus the $\mathrm{mSv} / \mathrm{h}$ value was very low and extraction of this value from the OSL calibration data was ignored (Table 1).

\begin{tabular}{|l|l|l|l|}
\hline \multirow{2}{*}{$\begin{array}{l}\text { Position } \\
(\mathbf{c m})\end{array}$} & \multicolumn{2}{|l|}{ OSL Mean Value (mSv) } & $\begin{array}{l}\text { GM Mean Reading } \\
(\mathbf{m S V})^{*}\end{array}$ \\
\cline { 2 - 3 } & Hp10 & Hp007 & \multicolumn{1}{|l}{} \\
\hline 30 & 1.67 & 1.9 & 1.32 \\
\hline 50 & 0.59 & 0.77 & 0.53 \\
\hline 100 & 0.14 & 0.18 & 0.15 \\
\hline
\end{tabular}

*The $\mathrm{mR}$ reading was converted by $9.63(\mathrm{mSv} / \mathrm{R})$ to $\mathrm{mSv}$.

Table 1: The mean OSL and GM reading value converted to equvalent dose under calibration geometry with I-131 source.

In Figure 2 the inverse square law consistency in GM and OSL measurements regarding to calculation dose values were shown. The calculated dose rate at different radial distances of $30 \mathrm{~cm}, 50 \mathrm{~cm}$ and $100 \mathrm{~cm}$ from I-131 source free in air was $1.45 \mathrm{mSv} / \mathrm{h}, 0.52 \mathrm{mSv} / \mathrm{h}$ and $0.13 \mathrm{mSv} / \mathrm{h}$ respectively. The inverse square law consistency in GM and OSL measurements were shown in Figure 2 (the regression value was $\mathrm{R} 2=0.99)$ regarding to calculation dose values.

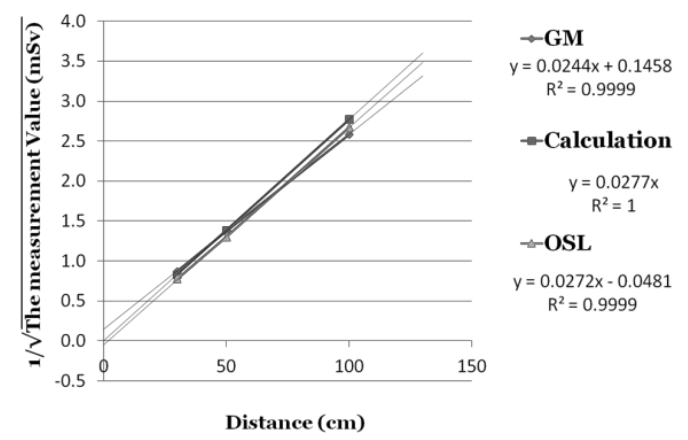

Figure 2: The inverse square law consistency in GM and OSL measurements regarding to calculation dose values were shown.

The mean dose results from OSL for a year to nuclear medicine department staff for whole body personnel dose monitoring was 0.80 $\mathrm{mSv} / 2 \mathrm{mon}$ and the standard deviation was $0.75 \mathrm{mSv} / 2 \mathrm{mon}$. After administration of $100 \mathrm{mCi}$ activity I-131 to specific patient the high dose response of OSL's was tailored each day. The OSL badge dosemeter was placed on the left pectoral muscle. Depending on the treatment period, each patient used 2-3 OSL badge dosemeters per day. In this way, the time integration would be traced and the range was 9.88- $83.6 \mathrm{mSv}$. The accumulated dose was calculated by summing values. The average and standard deviation of dose according to this therapeutic value was $97.5+32.6 \mathrm{mSv}$. The calculations was done by using excel (Microsoft) program.

\section{Conclusion}

The calibration process with encapsulated I-131 source for usage of OSL's was investigated in hospital environment. The inverse square law consistency was found in both GM and OSL dose values.

Irradiation of OSLs is typically performed using a $90 \mathrm{Sr} / 90 \mathrm{Y}$ beta source, although the use of X-ray generators is being investigated [11]. The OSL decay curves after exposure to high-LET radiation (He and heavier) are faster than those after exposure to low-LET radiation (gamma, beta and high- energy protons) as a consequence of the high doses within the charged-particle tracks created by high-LET radiations. So, the type and energy of radiation in the calibration phase will be better reflected in the OSL response. The reliable use of OSLs in whole body dosimetry of 9 staff based on I-131 calibration source could be precisely analyzed. On the other hand the high dose measurement capability of OSL was provided during administered of a high activity I-131 for ablation of thyroid tissue in 5 patients.

This calibration process is helpful for confidence of OSL detectors used for dosimetry of staff and patients treated with high activity I- 131 .

\section{References}

1. Vanhavere F, Carinou E, Donadille L, Ginjaume M, Jankowski J, et al. (2008) An overview on extremity dosimetry in medical applications. Radiat Prot Dosimetry 129: 350-355.

2. Smart R (2004) Task-specific monitoring of nuclear medicine technologists' radiation exposure. Radiat Prot Dosimetry 109: 201-209.

3. http://onlinelibrary.wiley.com/doi/10.1002/9780470977064.fmatter/pdf

4. Botter-Jensen L, McKeever SWS, Wintle AG (2003) Optically stimulated luminescence dosimetry. Elsevier.

5. Sommer M, Freudenberg R, Henniger J (2007) New aspects of a BeObased opticially stimulated luminescence dosemeter. Radiation Measurements 42: 617-620.

6. Sommer M, Jahn A, Henniger J (2008) Beryllium oxide as optically stimulated luminescence dosemeter. Radiation Measurements 43: 353-356.

7. Yukihara EG, McKeever SWS, Akselrod MS (2014) State of art: Optically stimulated luminescence dosimetry-Frontiers of future research. Radiation Measurements, 7: 15-24.

8. Sommer M, Jahn A, Praetorius RM, Sommer D, Henniger J (2012) A $\mathrm{mm}$-scale dosimetry system based on optically stimulated luminescence of beryllium oxide for investigation of dose rate profiles in constricted environments-12219. WM2012 Conference. Phoenix, AZ.

9. Lombardi $\mathrm{MH}$ (2006) Radiation safety in nuclear medicine. Taylor \& Francis Group, 2: 38.

10. Smith DS, Stabin MG (2012) Exposure rate constants and lead shielding values for over, 100 radionuclides. Health Phys 102: 271-291.

11. Andersen CE, Bøtter-Jensen L, Murray AS (2003) A mini X- ray generator as an alternative to a $90 \mathrm{Sr} / 90 \mathrm{Y}$ beta source in luminescence dating. Radiat. Meas. 37: 557-561. 